\title{
Um sarau para o povo
}

Resumo: No bairro do Campo Limpo, na periferia de São Paulo, acontece periodicamente um evento cuja marca registrada é a liberdade de todos os participantes em mostrar, ouvir e conhecer mais sobre poesia, música e manifestações culturais diversas. O Sarau do Binho reúne pessoas de diversos bairros e de cidades vizinhas interessadas em cultivar a cultura - dando origem inclusive a movimentos que se espalham por outras regiões do estado. Nesse depoimento, o idealizador do Sarau conta um pouco de suas experiências com a leitura e a poesia, que conheceu mais por vontade própria do que por educação formal, e fala como cultivar e destacar a cultura que nasce em lugares inusitados da cidade.

Palavras-chave: poesia, literatura, cultura popular, sarau, São Paulo.
Abstract: At Campo Limpo district, in São Paulo suburbs, from time to time an event happens and its trade-mark is the freedom that all participants have to show, listen and learn more and more about poetry, music and several cultural events. Binho's Soirée brings together people from different neighborhoods and surrounding towns interested in cultivating culture - giving origin, moreover, to movements that spread to other parts of the state. In this testimony, the founder responsible for the Soirée tells a little about his experiences with reading and poetry, which knew more willingly than by formal education and tells how to cultivate and stand out the culture that arises in unusual places in the city.

Keywords: poetry, literature, popular culture, soirée (evening concert), São Paulo.

Robinson Padial, o Binho, é o que se pode chamar de agitador cultural. Os frequentadores de seu bar, no Campo Limpo, distrito da cidade de São Paulo, no entanto, talvez nunca tenham pensado em definições para ele - nem para o espaço que disponibiliza todas as segundas-feiras para as exibições de poesia e música feitas por quem aparece por ali. $O$ Sarau do Binho reúne escritores, cantores, músicos e outros artistas populares que se revezam de forma livre, não ensaiada, com o único propósito de mostrar sua arte para quem estiver interessado em ver e ouvir. O distrito está localizado a cerca de 17 quilômetros do marco zero da cidade de São Paulo, na zona sudoeste. É conhecido pela presença de uma grande divisão social, onde vivem pessoas de baixa renda em favelas, em residências de baixo padrão e conjuntos habitacionais populares, ao lado de condominios horizontais e verticais de classe média e média alta. Além disso, o bairro possui grandes áreas de comércio popular e uma atividade industrial em processo de declinio, com alguns galpões e fábricas ainda em atividade. A região da Subprefeitura de Campo Limpo, que reúne distritos de Campo Limpo, Capão Redondo e Vila Andrade, contabiliza 550 mil moradores, um terço deles vivendo em pelo menos 237 favelas, segundo dados da Secretaria Municipal de Habitação e da subprefeitural. Desses 183 mil moradores de favelas, 80 mil concentram-se no Complexo Paraisópolis, composto pelas favelas Jardim Colombo, Porto Seguro e Paraisópolis. Os artistas do Sarau têm consciência da importância do evento, assim como seu idealizador. "O Sarau é um laboratório. Aqui as pessoas trazem suas criações e aprendem o gosto por ler e escrever", explica Binho. Do laboratório popular, mais do que textos, sai também a consciência cidadã fortalecida. Neste depoimento, Binho conta um pouco de como essa história começou e se ampliou.

1. Disponível em: <http:// portal.prefeitura.sp.gov. $\mathrm{br} / \mathrm{subprefeituras/spcl/}$ dados/historico/0001> Acessado em 27 jan. 2010. 
comunicação \& educação • Ano XV • Número 1 • jan/abr 2010

Nasci aqui mesmo no Campo Limpo, em 1964. Minha mãe era dona de casa e meu pai, maluco: era mestre de obras, mas gostava de cinema e se aventurou pelo mundo da música, das imagens. Quis fazer filmes, dizia que era o zorro brasileiro. Acho que essa parte de maluquice, de fazer coisas diferentes, um pouco herdei dele. Sempre gostei muito de ler. Da seção de futebol do jornal, passei às colunas de quem escrevia no mesmo jornal e, depois, aos livros. O que havia na escola, eu lia. Quando queria mais, ia do Campo Limpo até Pinheiros, na biblioteca pública, buscar livros que não tínhamos no nosso bairro.

Acho que ler traz inspiração para escrever. Quanto mais a pessoa lê, mais e melhor ela consegue escrever. Gosto de muitos estilos, leio de tudo - de Lavoura arcaica a Vida secreta das plantas. Mas um dos livros que mais me marcaram na vida foi Grande Sertão: Veredas. Costumo dizer que esse é o maior livro de autoajuda que existe, pois o Riobaldo, com aquela coragem dele, encoraja a gente também. Depois li outros livros do Guimarães Rosa - Sagarana, Corpo de baile. Gosto do estilo dele por causa da oralidade, com a qual me identifico. A leitura flui.

Sou dono desse bar há quinze anos. Antes disso, vivi três anos fora do país. Lavei carros na Itália, lavei pratos na Inglaterra e trabalhei como voluntário num kibutz em Israel. Voltei ao Brasil pela instabilidade de ficar fora do país, e também pela insegurança da situação política em Israel. Algumas vezes tínhamos de andar escoltados, pois a questão palestina era muito tensa. Lá, são sempre os palestinos que fazem os trabalhos mais pesados. Lá, são como os nossos nordestinos daqui.

Antes de viver fora do país, trabalhava com marcenaria, instalação de persianas. Mas, quando voltei, decidi abri o bar que tenho até hoje - o que é um paradoxo, porque eu não tenho dom para ser patrão. Quem é poeta não se dá com negócios. Gostaria que o bar fosse, na verdade, mais um espaço cultural do que um bar. Gostaria de fazer um anexo para organizar cafés filosóficos, debates, exibição de filmes. Por enquanto ainda não é possível, mas quem sabe no futuro?

E essa vontade de ser poeta veio com as leituras, mas me faltava organização para tentar escrever. Até que, em 1995, fiz um curso de biodança e, em uma das aulas, desenvolvemos atividades envolvendo poesia. Então, a partir daquelas experiências, comecei a escrever sobre o cotidiano, sobre coisas que me incomodavam ou me agradavam, sobre as coisas em que eu acreditava. Sobre minha vida no Campo Limpo, sobre o Brasil, sobre a América Latina.

E foi aí que surgiu a ideia do Postesia, um projeto que nasceu como luz em uma noite de semiescuridão. Desde 1995, eu organizava no bar a Noite da Vela. Todas as segundas-feiras, as pessoas se reuniam no bar para ouvir músicas que não tocavam nas rádios - Ravi Shankar, Pink Floyd, Milton Nascimento, Enio Moricone. Fazíamos isso para relaxar, conhecer músicas diferentes. As pessoas apresentavam os lados $B$ dos discos de que gostavam mais. E entre uma música 
e outra, às vezes alguém, contagiado pela luz de velas, pelo som e pela cerveja, resolvia ler uma poesia.

Numa dessas noites, perguntei-me: e se a gente colocasse poesia nos postes? Assim organizamos o Postesia, em 1997. Na época das eleições, eu e um grupo de amigos saíamos de madrugada, retirávamos as placas dos políticos das ruas, pintávamos novamente e devolvíamos alguns dias depois, com poesias. Fizemos isso de 1997 a 1999, e entre 1998 e 1999 fizemos também o Postura, quando pendurávamos pinturas nos postes. Convidávamos conhecidos para participar, amigos, pessoas do bairro. Elas diziam: "Eu não sei pintar", e a gente respondia: "Não precisa pintar, é só colorir". E elas faziam coisas lindas, que depois espalhávamos pela cidade.

Dois anos depois de termos feito o Postesia, pensei em reunir as poesias que tinha escrito naquela época e publicá-las. Então, vendi uma linha telefônica - naquela época, elas ainda valiam alguma coisa - e publiquei um livro, em 1999, com meus poemas.

Por essa altura já conhecia outros poetas e artistas, tanto do Campo Limpo como de outros lugares. Teve até uma história engraçada envolvendo um artista plástico do Embu, o Levi, que acompanhava o aparecimento das poesias nos postes e ficava curioso para saber quem eram as pessoas que faziam aquilo. Naquela época, não aparecíamos como

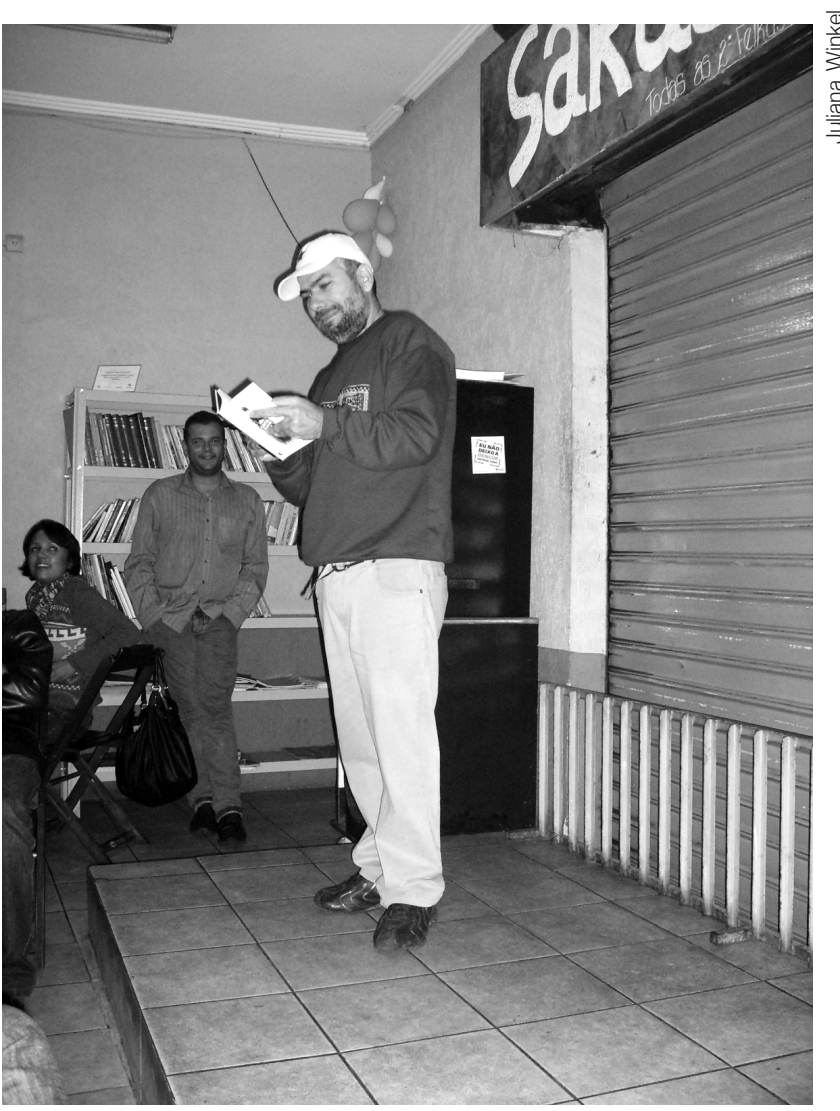

Binho apresentando o Sarau: encontro cultural na periferia. autores do projeto, pois poderia haver problemas com os políticos donos das placas, é claro. Quase um ano depois, conversando com um amigo meu, o Levi comentou sobre as poesias e esse amigo nos apresentou.

Por essa época, já fazíamos alguns saraus esporadicamente. Com o tempo e o aumento de pessoas interessadas, o intervalo entre a realização deles foi diminuindo. Logo os saraus passaram a ser mensais e, desde 2004, acontecem todas as segundas-feiras, no Bar do Binho. Algumas vezes, participamos também dos Sarais da Cooperifa ${ }^{2 *}$, que também reúne para se ler poesia.

2. Disponível em: <http:// www.expediciondondemiras.blogspot.com/>

* A Cooperativa Cul tural da Periferia (Cooperifa) ocorre todas as quarta-feiras, das oito à meia-noite, no bairro de Piraporinha, zona su de São Paulo. Criada em 2000, foi idealizada pelo poeta Sérgio Vaz com objetivo de reunir artistas da periferia e desenvolver atividades culturais, como teatro e exposição de fotografia em praças bares, galpões e diversos lugares. N.E. 
comunicação \& educação • Ano XV • Número 1 • jan/abr 2010

\section{SARAU: PONTO CULTURAL}

O Sarau tem espaço para músicos, cantadores, pessoas de teatro, cinema, artes plásticas e principalmente leitura de poesias, inéditas ou não. Qualquer um que quiser mostrar algo que produziu, ou alguma obra que ouvi ou leu, pode participar. O espaço é frequentado por gente de todas as idades e, nessa atmosfera de literatura, música e artes em geral, as pessoas são incentivadas a ler. Colocamos livros nas mesas e, num canto do bar, fica uma minibiblioteca. Enquanto a pessoa come um pastel e toma uma cerveja, ela esbarra nos livros.

O Sarau é um laboratório. É como se fosse uma nova escola, uma nova maneira de buscar informações. As pessoas compartilham seus conhecimentos, suas leituras, e assim produzem novas coisas e vão aprendendo. Gente que não se interessava pela arte começa a se interessar. Muitos visitantes do Sarau escolhem os livros a partir das poesias que ouvem aqui. Por exemplo, alguém vem e recita Navio negreiro, de Castro Alves. Então, quem ouve, interessa-se pelo tema e vai buscar, procura saber mais sobre essa época da história, ou sobre quem escreveu o poema.

Tem muita gente que vem aqui, começa a ouvir as poesias e logo está levando livros, ou ressuscitando coisas que estavam na gaveta, ou escrevendo poemas novos para ler depois. A partir do grupo, as pessoas começam a buscar conhecimento. Quase todas as pessoas que hoje participam do Sarau, antes, eram apenas frequentadores. E aprendem com o que o outro faz. Temos um amigo, por exemplo, que toda vez que sobe no palco para ler alguma coisa

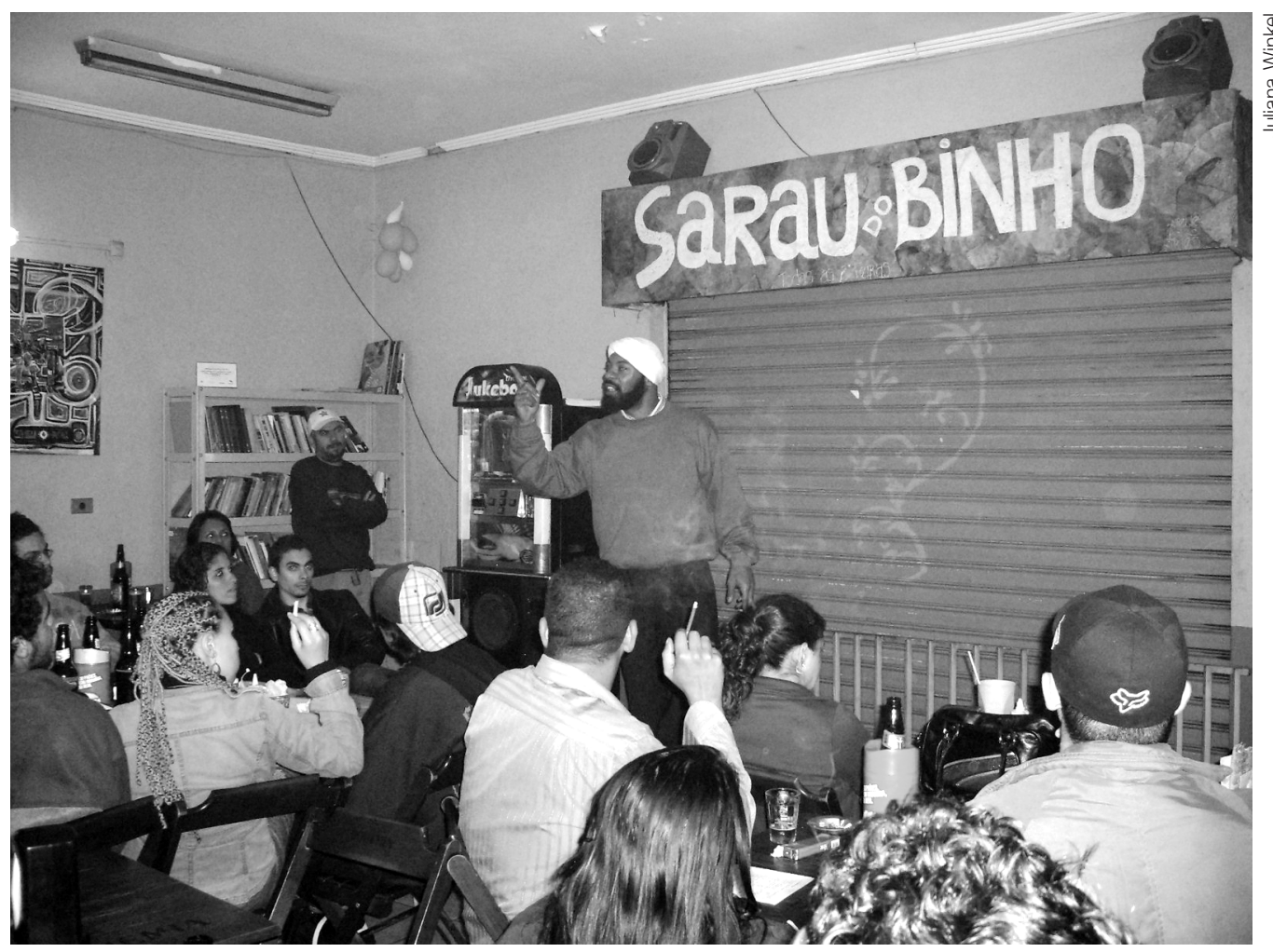

Declama o de poesia: Para participar do sarau, basta ter algo a apresentar e vontade de se expressar. 
começa dizendo: "Não sou poeta p... nenhuma". E em seguida lê uma poesia ótima que escreveu.

Outra coisa interessante é que reunimos pessoas de gostos bastante diferentes. Recebemos gente de todas as partes de São Paulo, e mesmo de outras cidades. De Embu das Artes, até de Arujá. Temos um amigo angolano que vem sempre de Arujá para os saraus. Tem gente que gosta de samba, outros de rock. Mas a literatura rechaça preconceitos, rechaça o racismo. E fortalece o respeito pelo outro, o interesse pela cultura do outro. Isso é o que incentivamos aqui.

\section{MAIS DE MIL LIVROS NO BAR}

A ideia da biblioteca começou quando eu trouxe alguns livros de casa para deixar no bar e emprestar para quem quisesse ler. Aos poucos, as pessoas começaram também a trazer seus livros e fomos acumulando. Hoje, tenho mais de mil livros que vou revezando na estante do bar. Temos livros sobre todos os assuntos - romance, educação, arte, infantil. Muita gente leva os livros e traz depois de ler, mas tem outras que não trazem mais. Mas isso não é problema, porque a ideia é justamente que esses livros se espalhem.

Outras iniciativas começaram a surgir a partir dos saraus. A Caminhada Donde Miras, por exemplo, tem o bar como ponto de encontro. Tivemos essa ideia em 2007, quando eu conversava com meu amigo Serginho, também poeta, sobre a vontade de conhecer a América Latina. Então pensamos em fazer isso a pé, pois caminhando se consegue agregar mais pessoas. Reunimos poemas que nós dois tínhamos escrito e publicamos um livro pelas Edições Toró, Dois poetas e um caminho, para vender durante as caminhadas. E o nome da caminhada nasceu justamente do verso de um poema do Serginho, sobre Che Guevara.

Por enquanto, fizemos viagens somente dentro do Brasil. Fomos a Curitiba em janeiro de 2008, depois a Cananeia em julho. A mais recente, uma caminhada caipira, foi de São Paulo a Botucatu, entre dezembro do ano passado e janeiro de 2009. Participam da expedição sempre entre 20 e 30 pessoas. Levamos meu carro como apoio durante a viagem. A cada cidade, falamos com artistas locais e reunimos gente para fazer saraus ao ar livre. A ideia, sempre, é conhecer o que é feito em cada lugar, além de mostrar o que fazemos. Temos encontrado coisas muito interessantes, uma receptividade muito boa. Produção de música, de arte, de teatro. Todos os lugares por onde passamos têm história, cultura para compartilhar.

Há o objetivo de fazer Caminhadas mais longas, para outros países da América Latina. Por enquanto ainda é inviável realizar essas expedições mais distantes, pois a maioria dos viajantes não pode ficar muito tempo afastada do trabalho. Mas pretendemos caminhar para o Chile, o Peru e outros países vizinhos, levando nossa cultura e conhecendo a cultura e os idiomas desses lugares. 
comunicação \& educação • Ano XV • Número 1 • jan/abr 2010

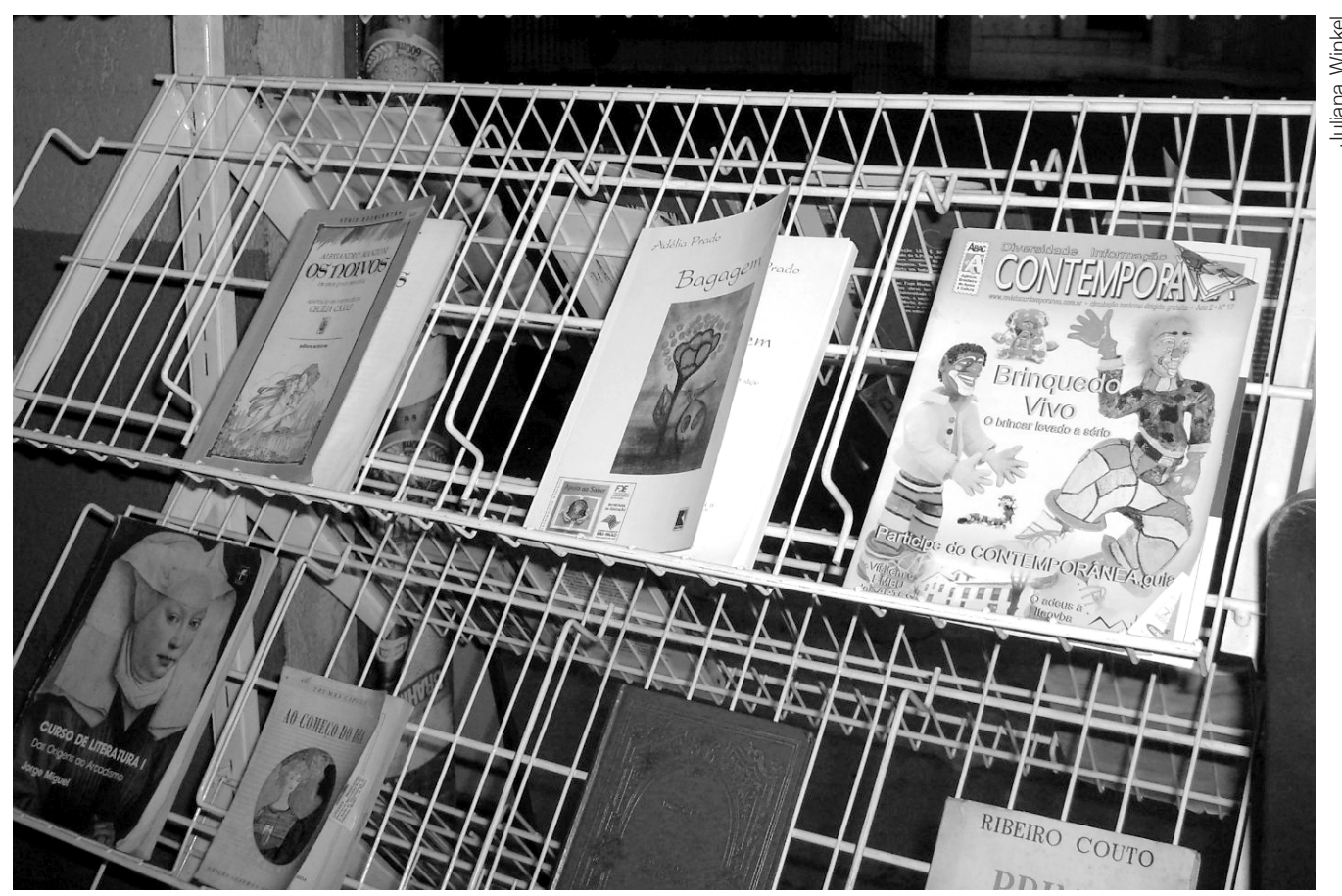

Estante entrada: Os livros ficam espalhados pelo bar, à espera de quem se interesse por levá-los para casa.

\section{BICICLETA E ÍNDIOS}

O projeto da Bicicloteca começou durante as Caminhadas Donde Miras. Conforme vamos caminhando, batemos nas casas oferecendo livros e arrecadando outros. Normalmente, as pessoas têm livros para doar. Então fazemos essa troca, retiramos em uma casa e deixamos na outra. Entre agosto e setembro de 2009, pretendemos deixar a bicicleta em um ponto de ônibus do Campo Limpo, também para trocar livros, com o apoio do Programa para a Valorização de Iniciativas Culturais (VAI), organizado pela Secretaria Municipal da Cultura. Desejamos fazer as caminhadas dentro de São Paulo também, a partir de agosto. Ir de um bairro a outro trocando livros, organizando eventos literários nas comunidades e nas favelas.

O contato com os índios Guarani começou a partir do meu interesse em aprender o idioma para usar nas Caminhadas. Um dos objetivos da Caminhada é justamente que, em cada trecho, a gente tenha contato com o idioma original daquela região. Acho isso muito importante, porque, quando se conhece a língua de um povo, se compreende e se respeita aquele povo. Quando você não conhece a língua, não conhece a cultura, é muito mais fácil passar com um trator por cima. E o povo Guarani é numeroso, existem mais de 100 mil pessoas que falam essa língua na América Latina. Por isso achei importante conhecer.

Primeiro comecei a estudar o guarani do Paraguai, com uma professora de lá, e depois passei a estudar o guarani que se fala no Brasil. Eles são parecidos, mas têm características próprias. Um professor da língua, que tinha uma escola no bairro de Pinheiros, hoje mora na aldeia que fica em Parelheiros, 
Um sarau para o povo • Juliana Winkel

lecionando ali. Minha filha Naiana, inclusive, tem estudado guarani lá. Foi a partir daí que começamos a organizar grupos para interagir com os índios.

Chega-se às aldeias por um caminho que passa pelo litoral, circundando as cidades de Itanhaém e Cananeia. Somos sempre recebidos por uma família que nos leva até os outros da aldeia. Eles sabem quem está se aproximando e é preciso chegar com respeito. Quando estivemos lá, conhecemos um pouco da cultura, das tradições e da religiosidade deles. Fomos recepcionados pelas famílias e recebemos uma bênção na casa de rezas. Um coro de crianças cantou para nós durante quase duas horas, com uma afinação perfeita. Levamos até algumas poesias, mas essa visita foi um aprendizado muito maior para nós. Eles não têm uma cultura escrita, mas são pura poesia.

Acho que a atividade fundamental para que todas essas iniciativas aconteçam é o Sarau. Se ele não existisse, não teríamos conseguido fazer as outras coisas. Seria muito mais difícil reunir as pessoas. Aos poucos, estamos conseguindo criar um espaço de pertencimento e referência cultural no Campo Limpo, entrelaçando várias vertentes culturais - e expandindo isso também para outras regiões, conhecendo outros lugares e outras culturas.

Ir e ir e ir

Quero ver onde essa

América se desmorena

E se constrói

Onde se diz negra

Onde se desmestiça

E se desmistifica

Onde se andina

E se desanda

Quero ver

Onde o samba é Gardel

Onde o tango é Noel

Onde a fala é o silêncio dos pampas

A Cordilheira, a Mantiqueira

Onde o ferro é cobre

Onde Itabira é Temuco

Onde Neruda é Drummond

Onde o guarani é oficial

Onde o Morumbi és La Bombonera

Onde o Chile é Allende

Onde nenhum salvador é Pinochet

Quero ver quero ver

Onde o Paraguay venceu

Onde Afonsina se entregou

Onde o Brasil se Argentina mais

Onde o Uruguai é mais Galeano

E onde eu sou mais ou menos brasileiro

Quero ver quero ver 
comunicação \& educação • Ano XV • Número 1 • jan/abr 2010

\section{Será que eu consigo?}

Será que consigo?

Em verbos de língua minha dizer isto:

Os dias que não banho tomo são mais limpos.

Gostaria de estar fedendo a nada.

Me acostumo a não chorar

só pra ver se deus me volta.

Cada um está principiado desde o sempre

com aquele medo

de um dia não mais pernoitar em si mesmo.

Pessoas com prática de elogiação

crescem a gente.

E de diminuir o bastante da gente

isso sabem fazer muitos.

Com um revólver na cintura

se compram miudezas de encrencas.

Quem apanha esquece mais difícil.

\section{Triste aliança}

Um Paraguai enviuvado

Mantido guarani resistente

Devolvendo a guerra que lutou

Via free shop

Um Brasil ao sul-balterno

E no comando um duque de caixões

A mando de uma Inglaterra feliz, de longe, mas happyssima

Um Uruguai gigante desfronteirado

Esparramando pampas

Uma rival Argentina, arquiniamiga

A trindade derrotando Solano e os seus

E mandando antepassados de Solano Trindade

Pra Cerro Corá e trincheiras adjacentes

Em busca de sangue e alforrias

Um Chile distante cortante

Pacífico, ainda não pinochetizado

Mentiras e verdades que já ganharam práticas

Nas costas das cordas

Cordilheiras chicoteantes

Quero mais saber mais

(Robinson Padial - Binho)

(Do livro: Donde miras: dois poetas e um caminho. São Paulo: Edições Toró, 2007. Disponível em: <http://www.edicoestoro.net/attachments/011_donde_miras_binho.pdf >.) 